\title{
Primary cutaneous CD30+ anaplastic large T cell lymphoma. A series of nine cases
}

\author{
León Felipe Ruiz-Arriaga ${ }^{1}$, Ixchel Landgrave-Gómez², Sonia Toussaint-Caire ${ }^{1}$, Rosa María Lacy-Niebla ${ }^{1 *}$ \\ and María Elisa Vega-Memije ${ }^{1}$ \\ 'Secretaría de Salud, Hospital General "Dr. Manuel Gea González", Department of Dermatology; ${ }^{2}$ Hospital Ángeles Acoxpa. Ciudad de México, \\ Mexico
}

\begin{abstract}
Introduction: CD30+ anaplastic large T cell lymphoma is a cutaneous primary lymphoma in which there is no evidence of systemic disease; histopathological study is required for its diagnosis. Objective: To present the cases diagnosed with primary cutaneous CD30+ anaplastic large T-cell lymphoma over a 24-year period in Hospital General "Dr. Manuel Gea González" Department of Dermatology. Method: Retrospective study. Descriptive statistics was carried out. Information was collected on gender, age, clinical characteristics, complementary test results, previous and current treatments, histopathological studies reports and immunohistochemistry test results. Results: Of 29,309 records, nine patients (0.000034\%) with a diagnosis of CD30+ anaplastic $T$ cell lymphoma were found. Histopathological and immunohistochemical diagnosis was confirmed by two certified dermatopathologists. Average age was 61.2 years, and there was a predominance of the female gender, with initial clinical presentation as a papular or nodular lesion and varied topography. Conclusions: The prognosis of CD30+ anaplastic large $T$ cell lymphoma in the studied population was dependent on clinical stage. The treatment at early stages has favorable results.
\end{abstract}

KEY WORDS: Anaplastic CD30+ large T cell lymphoma. Primary cutaneous lymphoma. Primary cutaneous lymphoproliferative disorder.

\section{Introduction}

Primary cutaneous T-cell lymphoma (PCTCL) is a skin lymphoma where there is no evidence of systemic disease (extracutaneous) at diagnosis.

According to the 2016 World Health Organization Lymphoid Neoplasms Classification Review, primary CD30+ T-cell lymphoma is the second most frequent, with 25 to $30 \%$, after mycosis fungoides. ${ }^{1}$ This classification includes the spectrum that ranges from lymphomatoid papulosis to primary anaplastic large cell lymphoma (PALCL), passing through intermediate cases.
PALCL is a rare entity, and its incidence is not known with certainty, possibly due to the difficulty for separating this pathology from the of CD30+ primary cutaneous lymphomas spectrum. In a 2008 review of the United States National Institute of Cancer database, 157 cases of CD30+ primary cutaneous T-cell lymphoma were identified in a 30 -year period. ${ }^{2}$

Its diagnosis requires histopathological study, with excisional over incisional biopsy being preferred. Histologically, cells with abundant pale eosinophilic cytoplasm are observed; the nucleus can be round or pleomorphic (usually horseshoe-shaped), with a prominent nucleolus. One fourth of lymphocytes can be
Gac Med Mex. 2019;155:118-123

Contents available at PubMed www.gacetamedicademexico.com 
atypical, but they do not appear to be anaplastic. ${ }^{3}$ In the periphery of lesions or in ulcerated areas, reactive lymphocytes, histiocytes, eosinophils, and neutrophils can be present.

All patients with suspected PALCL should be staged in order to confirm or rule out systemic disease. Bone marrow aspiration is recommended in patients with no imaging-demonstrable systemic disease. ${ }^{4,5}$ Differential diagnosis should include lymphomatoid papulosis, transformed mycosis fungoides, systemic lymphoma, adult T-cell leukemia-lymphoma, Hodgkin's lymphoma and reactive lymphoid hyperplasia.

The treatment of small or not too large lesions is radiotherapy or excision with free margins; ${ }^{6}$ the treatment of choice in patients with widespread disease or multiple relapses is methotrexate monotherapy for up to three continuous years. ${ }^{7}$ In patients in whom this drug is contraindicated, the choice can be bexarotene (level of evidence $2 \mathrm{C}$ ) or interferon. ${ }^{8-11}$ In patients who failed to respond to a previous treatment, brentuximab/vedotin, gemcitabine, etoposide or liposomal doxorubicin monotherapy can be administered. ${ }^{4,12-15}$ Combined chemotherapy and allogeneic hematopoietic cell transplantation should be reserved for disseminated cases that fail to respond to the indicated treatment. ${ }^{6}$

Prognosis depends on multiple clinical and histopathological factors. At early stages, five-year survival is up to $97.5 \%$ for the disease classified as T1; when classified as T2, up to $93 \%$ and for T3-stage tumors, $77 \% .^{16,17}$

The purpose of this communication is to present nine cases that were diagnosed in our hospital as primary cutaneous CD30+ large T-cell anaplastic lymphomas over a 24-year period.

\section{Method}

In this retrospective study, Hospital General "Dr. Manuel Gea González" Dermatopathology Department database was reviewed looking for data from patients diagnosed with anaplastic T-cell lymphoma during the period from 1993 to 2016. Descriptive statistics was carried out.

Data were collected on gender, age (in years), clinical characteristics (topography, morphology and time of evolution), complementary test results, previous and current treatments, histopathological examination reports and immunohistochemical studies results.
Out of 29,309 records, nine patients diagnosed with CD30+ T-cell anaplastic lymphoma were found, which accounts for $0.000034 \%$.

Histopathological and immunohistochemical diagnosis was confirmed by two certified dermatopathologists. Hematoxylin and eosin staining and an immunohistochemical panel were performed, where CD3 ( $T$ cells), CD4 ( $T$ and dendritic cells), CD8 ( $T$ cells), CD20 ( $B$ cells), CD30 (immature precursor $T$ cells), epithelial membrane antigen (EMA, marker of multiple carcinomas), activin-like kinase receptor 1 (ALK-1, a proangiogenic protein), multiple myeloma oncogene 1 (MUM1, a marker for lymphomas) and Ki-67 (a protein that is necessary for cell proliferation, which reflects the neoplasm cell division index) were included.

Immunohistochemical staining was carried out with the standard technique and according to the manufacturer's instructions.

Five patients underwent general tests (blood count, blood chemistry, acute phase reactants), which were normal; three patients underwent imaging studies, without evidence of disseminated disease being identified.

\section{Results}

Nine patients were identified, with women being predominant; average age was 61.2 years, topography and morphology were varied and histological studies were consistent with lymphoma; all with CD30+ immunohistochemistry technique. No sample was discarded during the process. Main topography was the trunk and buttocks (four patients), as well as lower and upper limbs (four patients) and face and neck (three patients). Morphologically, the lesions were characterized by single or multiple papular erythematous tumor activity that progressed to nodular tumor lesions or erythematous-violaceous plaques with fine scales on their surface; average evolution time was two years and 20 weeks (ranging from four weeks to 10 years). Additional assessments and data included blood chemistry, blood count and complete physical examination; evidence of adenomegalies was found only in one patient. At the time of this report, three patients were under surveillance, with expectant management, four cases were lost to follow-up because they did not continue with their management at the institution by their own decision or because they were referred to a cancer center, one patient was on treatment with phototherapy and one more with methotrexate. 
Table 1. Cases of primary large cell anaplastic lymphoma diagnosed at Hospital General "Dr. Manuel Gea González" Dermatology Department, 1994 to 2017

\begin{tabular}{|c|c|c|}
\hline Case & Histopathological diagnosis & Immunohistochemistry staining results \\
\hline 1 & $\begin{array}{l}\text { Atypical lymphocyte infiltrate, probable T-cell anaplastic } \\
\text { Iymphoma }\end{array}$ & $\mathrm{CD} 3+, \mathrm{CD} 30+$ \\
\hline 2 & CD30+lymphoproliferative disorder & CD30+, EMA-, ALK1- \\
\hline 3 & $\begin{array}{l}\text { CD30+large cell anaplastic lymphoma (rich in neutrophils } \\
\text { and eosinophils) }\end{array}$ & $\mathrm{CD} 30+, \mathrm{CD} 3+, \mathrm{EMA}+, \mathrm{ALK} 1-$ \\
\hline 4 & CD30+ lymphoproliferative disorder & CD20-, CD3+, CD30+, Ki-67 $60 \%$ \\
\hline 5 & CD30+ lymphoproliferative disorder & AE1-3-, CD45+, CD3+, CD4+, CD30+. ALK1- cytokeratins, Ki-67 70\% \\
\hline 6 & CD30+ atypical lymphoid infiltration & $\mathrm{CD} 3+, \mathrm{CD} 30+, \mathrm{CD} 20-, \mathrm{CD} 4-, \mathrm{CD} 8-$ \\
\hline 7 & Cutaneous CD30+ T-cell lymphoma & $\mathrm{CD} 4+, \mathrm{CD} 30+$ \\
\hline 8 & $\begin{array}{l}\text { Mycosis fungoides associated with CD30+ } \\
\text { lymphoproliferative disorder }\end{array}$ & $\mathrm{CD} 3+, \mathrm{CD} 4+, \mathrm{CD} 8+, \mathrm{CD} 30+, \mathrm{MUM} 1+$ \\
\hline 9 & $\begin{array}{l}\text { CD30+ lymphoproliferative disorder suggestive of } \\
\text { anaplastic large T cell lymphoma }\end{array}$ & $\mathrm{CD} 3+, \mathrm{CD} 30+, \mathrm{MUM} 1+, \mathrm{Ki}-6740 \%$ \\
\hline
\end{tabular}

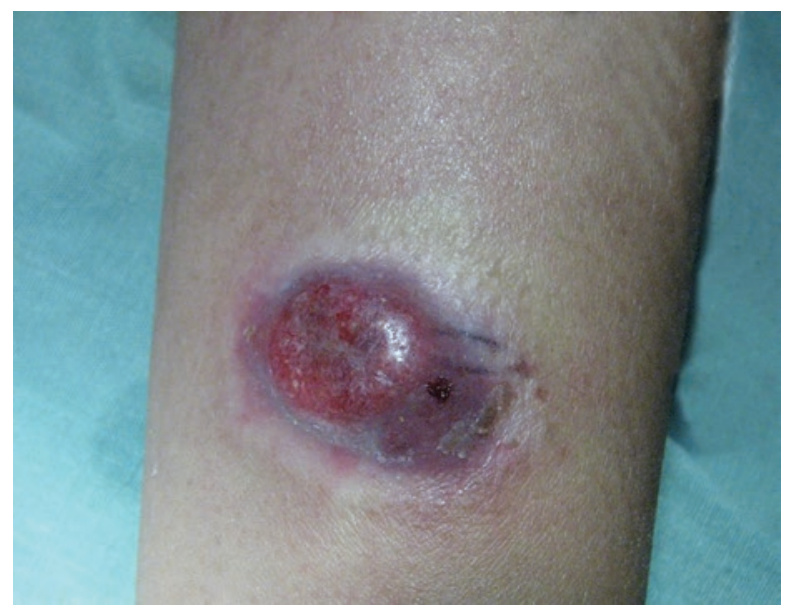

Figure 1. Case 1. Neoformation with tumor aspect on erythematous-violaceous plaque infiltrating left arm distal third.

Histologically, we found skin sections with parakeratosis and fibrin, epidermis with irregular acanthosis, as well as abundant spongiosis and neutrophil exocytosis and focal hyperpigmentation of the basal layer, with characteristic atypical lymphoid proliferation from the papillary dermis to the deep reticular dermis, with prominent, large, hyperchromatic and pleomorphic nuclei, as well as abundant eosinophilic cytoplasm and some cells of plasmocytoid appearance. Proliferation surrounded the blood vessels and in some areas invaded their walls. Table 1 summarizes the histological and immunohistochemical diagnoses of all nine cases. Figures 1 to 5 are clinical images representative of cases 1, 2, 3, 4 and 7; Figure 6 shows a representative histopathological study.

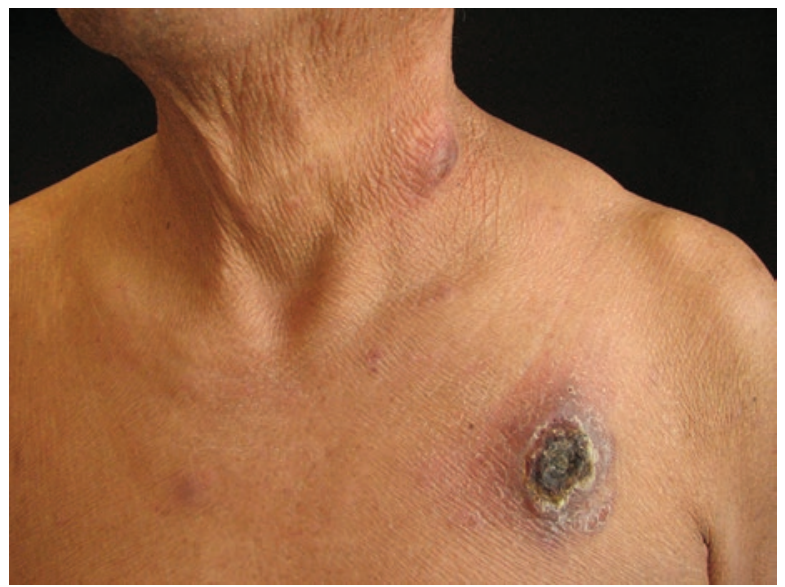

Figure 2. Case 2. Multiple lesions with tumor aspect in the neck and anterior trunk, the largest with bloody scab, scales and infiltration on palpation.

Ki-67-determined proliferation index was 40 to $70 \%$ in the cases it was assessed.

\section{Discussion}

PALCL is a rare entity, the incidence of which is not report with certainty. At Hospital General "Dr. Manuel Gea González", nine cases were diagnosed in a 24 year-period, which accounts for $0.000034 \%$ of a total of 29,309 recorded biopsies; the number of cases was rather low compared to other reports, such as Yu's series, where 157 cases are reported in 31 years. $^{2}$

Average age was 61.2 years (ranging from 23 to 82 years), which was similar to the 61 years reported 


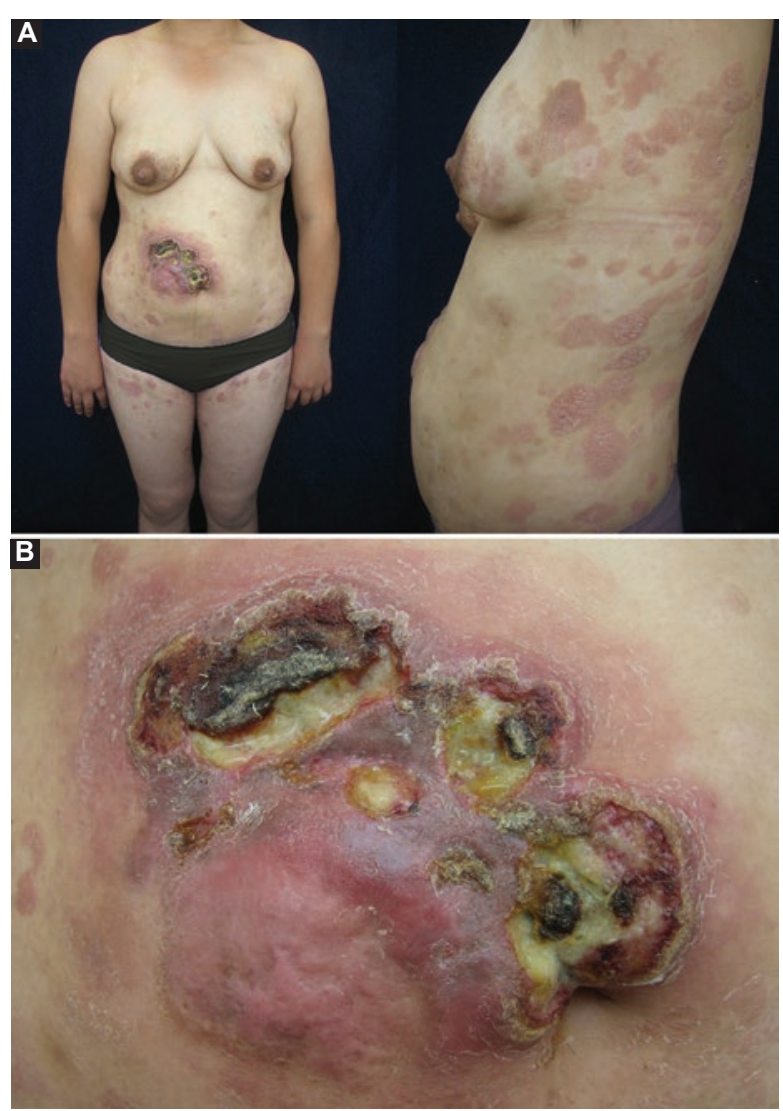

Figure 3. Case 3. A) Multiple erythematous-scaly plaques infiltrating the anterior and lateral trunk, as well as in thighs anterior portion, with a tumor lesion in the abdomen, where an exophytic lesion is identified. B) Closer view of the exophytic lesion, infiltrated and exulcerated with scabs.

in the literature. ${ }^{2}$ Of our nine cases, six were women $(66.6 \%)$ and three men, in contrast with the figures reported in the study of the United States National Cancer Institute, where they identified 157 cases, out of which $58 \%$ were males.

PALCL clinical presentation classically consists of solitary papules or nodules, grouped or multifocal, in the upper segment of the body (trunk and upper limbs), which persist for three to four weeks and tend to ulcerate over time. In our cases, seven patients started with papular erythematous lesions, which evolved into well-delimited erythematous-scaly plaques, some with infiltrated borders, ulcerated and firm in consistency. Five patients had trunk lesions, four had limb lesions, two had facial lesions and only one had neck lesions (some patients had one or more involved sites). In 20 to $42 \%$ of cases, spontaneous remission of the lesions can occur, which do not completely disappear, and more than $50 \%$ recur. ${ }^{6,18-21}$ Since patients were referred to the National Institute of Cancerology for specialized treatment, their evolution is unknown.

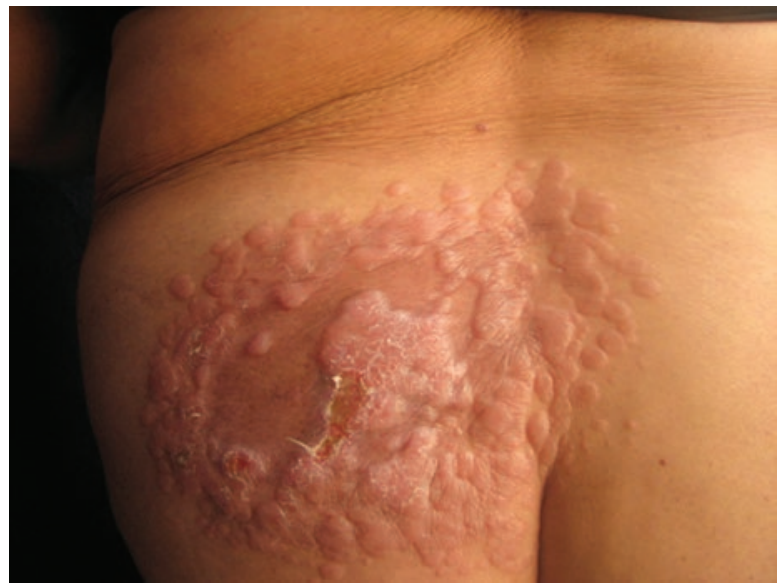

Figure 4. Case 4. Localized dermatosis to lumbosacral region, constituted of an irregular plaque, with multiple lesions, protruding in the surface, skin color, with atrophy and exulceration areas.

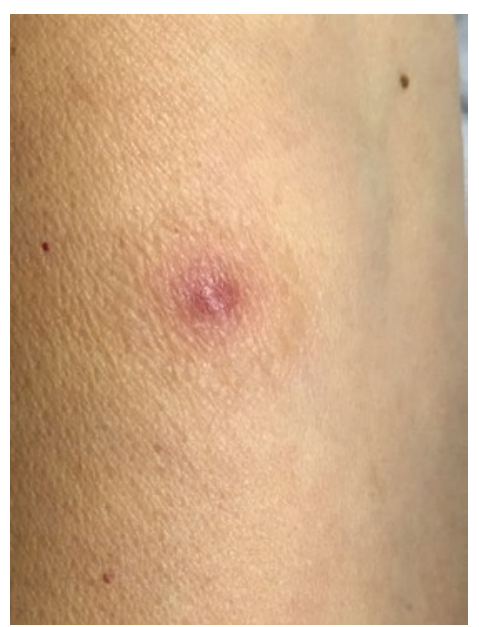

Figure 5. Case 5. Lesion of papular appearance, erythematous, with discrete scales on its surface at the anterior portion of the arm.

Histologically, the neoplasm is characterized by dense dermal infiltrate and sometimes it involves the epidermis. The infiltrate comprises cohesive clusters of large lymphocytes, which morphologically resemble those of systemic anaplastic large cell lymphoma. ${ }^{22}$ Histopathological sections showed a diffuse lymphocytic infiltrate, from the dermis to the subcutaneous cellular tissue, characterized by medium-large cells, with moderate pleomorphism and abundant eosinophilic cytoplasm, prominent nuclei and atypical mitoses, with some cells of plasmocytoid appearance. In one of our cases, infiltration to local vasculature was observed.

By definition, at least $75 \%$ of the tumor must express CD30; $1,4,23,24$ in addition, most lesions express CD4 and may have variable CD2, CD3 and CD5 loss. Lymphocytic cutaneous antigen is often present and, unlike systemic anaplastic large cell lymphoma, it 


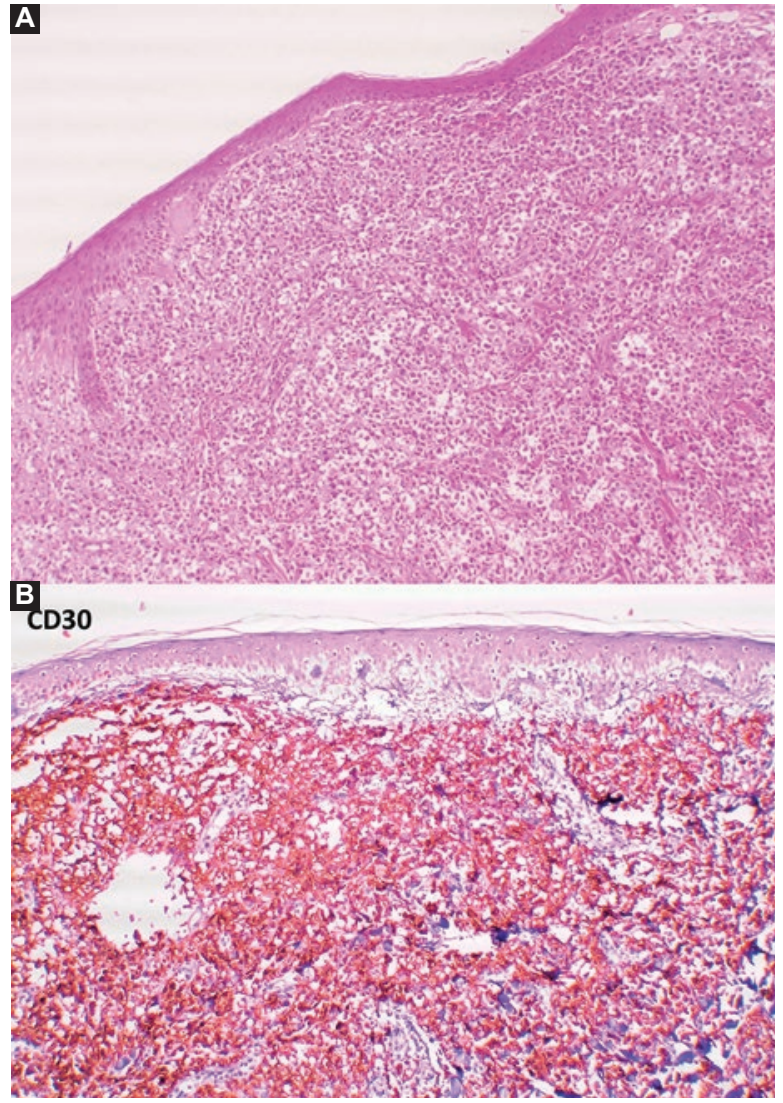

Figure 6. A) Histological image where the epidermis with flattening of interpapillary processes is observed; the dermis is occupied by an infiltrate in mantles of pleomorphic cells, some with clear cytoplasm, H\&E 10x. B) Histological section with intensely positive immunohistochemistry for the CD30 antibody, 10x.

does not express epithelial membrane antigen or ALK$11^{1,4,25}$ The nine cases we reported were positive for CD30, three were negative for ALK-1, seven were CD3-positive, two CD20-negative, one case was positive to epithelial membrane antigen and one negative; in three, Ki-67 high proliferation index was reported.

There are conditions that have been associated with PALCL, such as atopic dermatitis, hypersensitivity to mosquito bites, hemophagocytic lymphohistiocytosis and paraneoplastic syndrome of inappropriate antidiuretic hormone secretion, chronic myelogenous leukemia, chronic lichenoid keratosis and squamous cell carcinoma. ${ }^{26-35}$ Patient 5 in our series concomitantly suffered from advanced prostate cancer, and patient 8, mycosis fungoides prior to the PALCL diagnosis.

Carbamazepine therapy-associated PALCL has also been documented; ${ }^{36}$ in our cases, no patient had a history of having ingested this medication. The association between latitude increase and the prevalence of T-cell lymphoma, including PALCL, suggests a modulating effect of ultraviolet radiation. In our country, exposure to this type of radiation is common and might be a reason for the low incidence of these cases in our research.

The indicated treatment ranged from expectant behavior, due to short evolution, to management in a cancer center; one of the patients continued with low dose-methotrexate and, another, on treatment with phototherapy and electron bath therapy due to concomitance with mycosis fungoides. One patient only received palliative treatment given the coexistence of the lymphoma with end-stage prostate cancer.

Relapse after treatment tends to be limited to the skin, but $27 \%$ of cases have been reported to relapse with extracutaneous disease, half in the lymph nodes. ${ }^{17,37}$ Infiltration to internal organs can occur two to 10 years after diagnosis, according to different analyses, and it is not always associated with advanced T stage. ${ }^{17}$ Four patients continued on follow-up in the department; no disease progression or relapse has been observed in those who achieved remission.

\section{Conclusion}

We report nine cases of primary cutaneous CD30+ anaplastic large cell lymphoma, studied over a 24-year period; women were predominant, morphology and topography were diverse, mainly in the trunk and extremities. The lymphoma occurred mainly with single papular lesions that evolved into plaques or erythematous-violaceous lesions. Some lymphomas were associated with systemic disease, or with other neoplasms such as mycosis fungoides and prostate cancer, and had variable response to treatment. The importance of knowing the incidence and presence of this disease lies in the fact that the prognosis depends on clinical stage and, at early stages, it is highly favorable.

\section{References}

1. Cazzola M. Introduction to a review series: the 2016 revision of the WHO classification of tumors of hematopoietic and lymphoid tissues. Blood. 2016;127:2361-2364.

2. Yu J, Blitzblau R, Decker R, Housman D, Wilsn L. Analysis of primary CD30+ cutaneous lymphoproliferative disease and survival from the Surveillance, Epidemiology, and End Results Database. J Clin Oncol. 2008;26:1483-1488.

3. Brown RA, Fernandez-Pol S, Kim J. Primary cutaneous anaplastic large cell lymphoma. J Cutan Pathol. 2017:44:570-577.

4. Kempf W, Pfaltz K, Vermeer M, Cozzio A, Ortiz-Romero P, Bagot M, et al. EORTC, ISCL, and USCLC consensus recommendations for the treatment of primary cutaneous CD30-positive lymphoproliferative disorders: lymphomatoid papulosis and primary cutaneous anaplastic large-cell lymphoma. Blood. 2011;118:4024-4035.

5. Yang S, Khera P, Wahlgren C, Ho J, Jukic D, Geskin L, et al. Cutaneous anaplastic large-cell lymphoma should be evaluated for systemic involvement regardless of alk-1 status: case reports and review of literature. Am J Clin Dermatol. 2011;12:203-209. 
6. Liu HL, Hoppe RT, Kohler S, Harvell J, Reddy S, Kim Y. CD30+ cutaneous lymphoproliferative disorders: the Stanford experience in lymphomatoid papulosis and primary cutaneous anaplastic large cell lymphoma. J Am Acad Dermatol. 2003;49:1049-1058.

7. Vonderheid E, Sajjadian A, Kadin ME. Methotrexate is effective therapy for lymphomatoid papulosis and other primary cutaneous CD30-positive lymphoproliferative disorders. J Am Acad Dermatol. 1996;34:470-481.

8. Oliveira A, Fernandes I, Alves R, Lima M, Selores M. Primary cutaneous CD30 positive anaplastic large cell lymphoma: report of a case treated with bexarotene. Leuk Res. 2011;35:e190-e192.

9. Sheehy O, Catherwood M, Pettengell R, Morris TC. Sustained response of primary cutaneous CD30 positive anaplastic large cell lymphoma to bexarotene and photopheresis. Leuk Lymphoma. 2009;50:1389-1391.

10. French LE, Shapiro M, Junkins-Hopkins JM, Vittorio CC, Rook AH. Regression of multifocal, skin-restricted, CD30-positive large T-cell lymphoma with interferon alfa and bexarotene therapy. J Am Acad Dermatol. 2001;45:914-918.

11. McGinnis K, Junkins-Hopkins J, Crawford G, Shapiro M, Rook A, Vittorio C. Low-dose oral bexarotene in combination with low-dose interferon alfa in the treatment of cutaneous T-cell lymphoma: clinical synergism and possible immunologic mechanisms. J Am Acad Dermatol. 2004;50(3):375-379.

12. Oregel K, Everett $E$, Zhang $X$, Nagaraj G. Complete response in a critically ill patient with ALK-negative anaplastic large cell lymphoma treated with single agent brentuximab-vedotin. Expert Rev Anticancer Ther. 2016;16:279-283.

13. Wehkamp U, Oschlies I, Nagel I, Brasch J, Kneba M, Günther A, et al. ALK-positive primary cutaneous T-cell-lymphoma (CTCL) with unusual clinical presentation and aggressive course. J Cutan Pathol. 2015;42:870-877.

14. Duvic M, Talpur R, Wen S, Kurzrock R, David CL, Apisarnthanarax N Phase II evaluation of gemcitabine monotherapy for cutaneous T-cell lymphoma. Clin Lymphoma Myeloma. 2006;7:51-58.

15. Rijlaarsdam JU, Huijgens PC, Beljaards RC, Bakels V, Willemze R. Oral etoposide in the treatment of cutaneous large-cell lymphomas. A preliminary report of four cases. Br J Dermatol. 1992;127:524-528.

16. Savage KJ, Harris NL, Vose JM, Ullrich F, Jaffe ES, Connors JM, et al ALK- anaplastic large-cell lymphoma is clinically and immunophenotypically different from both ALK+ ALCL and peripheral T-cell lymphoma, not otherwise specified: report from the International Peripheral T-Cell Lymphoma Project. Blood. 2008;111:5496-5504.

17. Benner M, Willemze R. Applicability and Prognostic Value of the New TNM Classification System in 135 patients with primary cutaneous anaplastic large cell lymphoma. Arch Dermatol. 2009;145(12):1399-1404.

18. Bekkenk MW, Geelen FA, Van-Voorst-Vader PC, Heule F, Geerts M, Van-Vloten W, et al. Primary and secondary cutaneous CD30(+) lymphoproliferative disorders: a report from the Dutch Cutaneous Lymphoma Group on the long-term follow up data of 219 patients and guidelines for diagnosis and treatment. Blood. 2000;95:3653-3661.

19. Booken N, Goerdt S, Klemke CD. Clinical spectrum of primary cutaneous CD30-positive anaplastic large cell lymphoma: an analysis of the Mannheim Cutaneous Lymphoma Registry. J Dtsch Dermatol Ges. 2012;10:331-339.

20. Artemi P, Wong DA, Mann S, Regan W. CD30 (Ki-1)-positive primary cutaneous T-cell lymphoma: report of spontaneous resolution. Australas J Dermatol. 1997:38:206-208.

21. Biswas A, Tan B. Spontaneous regression of a childhood tumour with anaplastic histological features. Clin Exp Dermatol. 2012;38:318-320.

22. Paulli M, Berti E, Rosso R, Boveri E, Kindl S, Klersy C, et al. CD30/Ki-1-positive lymphoproliferative disorders of the skin: clinicopa- thologic correlation and statistical analysis of 86 cases: a multicentric study from the European Organization for Research and Treatment of Cancer Cutaneous Lymphoma Project Group. J Clin Oncol. 1995;13: 1343-1354.

23. Stein H, Foss HD, Dürkop H, Marafioti T, Delsol G, Pulford K, et al. CD30+ anaplastic large cell lymphoma: a review of its histopathologic, genetic, and clinical features. Blood. 2000;96:3681-3695.

24. Willemze R, Jaffe ES, Burg G, Cerroni L, Berti E, Swerdlow SH, et al. WHO-EORTC classification for cutaneous lymphomas. Blood. 2005; 105:3768-3785.

25. DeCoteau JF, Butmarc JR, Kinney MC, Kadin M. The t(2 $\square 5)$ chromosomal translocation is not a common feature of primary cutaneous CD30+ lymphoproliferative disorders: comparison with anaplastic large cell lymphoma of nodal origin. Blood. 1996;87:3437-3441.

26. Ishida M, Hodohara K, Yoshii M, Okuno H, Horinouchi A, Shirakawa A et al. Primary cutaneous anaplastic large cell lymphoma occurring in an atopic dermatitis patient: a case report with review of the literature with emphasis on their association. Int J Clin Exp Pathol. 2014;7:1735-1741.

27. Shimizu Y, Tanae K, Takahashi N, Kohri M, Arai E, Bessho M, et al. Primary cutaneous anaplastic large-cell lymphoma presenting with hemophagocytic syndrome: a case report and review of the literature. Leuk Res. 2010;34:263-266.

28. Basheer A, Padhi S, Nagarajan R, Boopathy V, Mookkappan S, Igbal N. Hemophagocytic lymphohistiocytosis in association with primary cutaneous anaplastic large cell lymphoma. Case Rep Hematol. 2014; 2014:384123.

29. Kang JH, Lee JH, Park HJ, Cho BK, Song $\mathrm{CH}$, Ock SM, et al. Anaplastic lymphoma kinase-positive anaplastic large cell lymphoma arising in a patient with hypersensitivity to mosquito bites. Korean J Fam Med. 2015;36:35-41.

30. Hirata Y, Yokote T, Nishiwaki U, Tsuji M, Hanafusa T. Syndrome of inappropriate antidiuretic hormone secretion associated with primary cutaneous anaplastic large cell lymphoma. Br J Haematol. 2012;157:412.

31. Charafeddine KM, Farchoukh LO, Khalifeh I. Primary cutaneous anaplastic large-cell lymphoma occurring in a case of chronic myeloid leukemia in remission. J Cutan Pathol. 2012;39:884-886.

32. Yanagi T, Shimizu T, Kodama K, Nemoto-Hasebe I, Kasai M, Shimizu H. CD30-positive primary cutaneous anaplastic large-cell lymphoma and definite squamous cell carcinoma. Clin Exp Dermatol. 2009;34:e293-e294

33. Newland KM, McCormack CJ, Prince H, Lade S. Cutaneous CD30 positive lymphoproliferative disorders with coexistent epithelial neoplasms: report of two cases. Australas J Dermatol. 2015;56:e83-e87.

34. Zhou P, Geng S, Li B, Wang J, Wang X, Xiao S. Keratosis lichenoides chronica in association with primary cutaneous anaplastic large cell Iymphoma. Int J Dermatol. 2014;53:e109-e112.

35. Fletcher CL, Orchard GE, Hubbard V, Whittaker SJ, Edelson RL, Russell-Jones R. CD30(+) cutaneous lymphoma in association with atopic eczema. Arch Dermatol. 2004;140:449-454.

36. Di-Lernia V, Viglio A, Cattania M, Paulli M. Carbamazepine-induced, CD30+, primary, cutaneous, anaplastic large-cell lymphoma. Arch Dermatol. 2001;137:675-676.

37. Benner MF, Willemze R. Bone marrow examination has limited value in the staging of patients with an anaplastic large cell lymphoma first presenting in the skin. Retrospective analysis of 107 patients. $\mathrm{Br} \mathrm{J}$ Dermatol. 2008;159:1148-1151. 